Mahmoud Y Taha

BVM\&S, MSc, PhD (Prof.)

Nadia M Al-Shakir

BDS, MSc (Lec.)

Nawal A Al-Sabawi

BDS,MSc (Lec.)

\section{Antibacterial Effect of Dentin Bonding Agents: (An in vitro Study)}

Department of Dental Basic Science

College of Dentistry, University of Mosul

Department of Conservative Dentistry

College of Dentistry, University of Mosul

Department of Conservative Dentistry College of Dentistry, University of Mosul

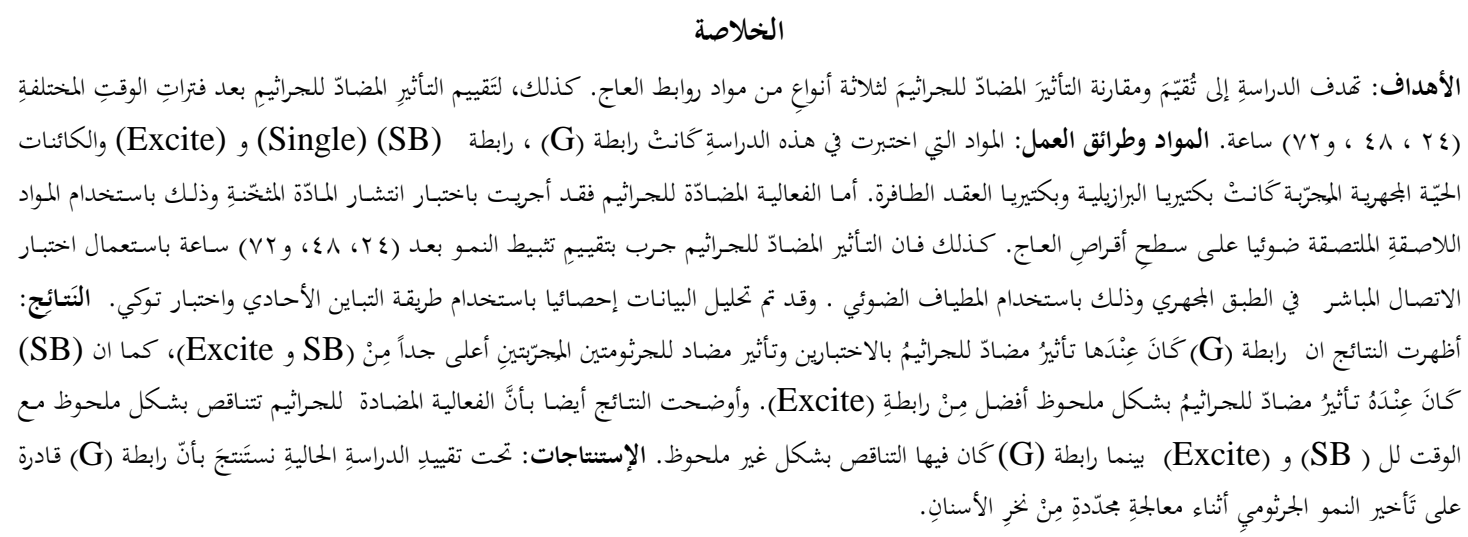

ABSTRACT

Aims: To evaluate and compare the antibacterial effect of three types of dentin bonding agents. Also, to evaluate the antibacterial effect after different time intervals (24, 48, and 72) hs. Materials and Methods: Materials tested in this study were G bond, Single bond (SB), and Excite bond. Tested microorganisms were Enterococcus faecalis (E. faecalis) and Streptococcus mutans (S. mutans). The antibacterial activity were investigated by agar diffusion test performed with adhesives cured on the surface of dentin discs. Also, the antibacterial effect were investigated by evaluation of growth inhibition after 24,48 , and $72 \mathrm{hrs}$ microplate direct contact test using spectrophotometer. The data were analyzed statistically using one way ANOVA and Tukey's test. Results: G bond had antibacterial effect by the two tests and against the two examined bacteria significantly higher than SB and Excite, also SB significantly had antibacterial effect better than Excite bond. The result also revealed that antibacterial effect of SB and Excite Bond significantly decreased by the time while $\mathrm{G}$ bond was not significantly decrease. Conclusions: Under the limitation of the present study, it is concluded that G bond is able to delay bacterial growth during restorative treatment of dental caries.

Key words: Dentin bonding agents, Enterococcus faecalis, Streptococcus mutans. Antibacterial activity.

Taha MY, Al-Shakir NM, Al-Sabawi NA. Antibacterial Effect of Dentin Bonding Agents: (An in vitro Study). Al-Rafidain Dent J. 2012; 12(2): 228-234.

Received: 14/9/2011 Sent to Referees: 19/9/2011

Accepted for Publication: 4/12/2011

\section{INTRODUCTION}

The complete removal of carious dentin during cavity preparation is a primary goal in the treatment of dental caries. However, dentin can still show a low level of infection after conventional caries removal. Moreover, when restorative materials are placed on the cavity wall, complete sealing at the bonded surface is not always achieved. Residual bacteria harboured on the excavated lesions and leakage of bacteria through microgaps after restorations are known to be the main cause of secondary caries and damage to the pulp. Therefore, the use of restorative materials, including adhesive systems, that maintain antibacterial activity may provide a supplementary treatment contributing to the suppression of residual infection and increasing the survival of the restored tooth. ${ }^{(1)}$

Recently, agar diffusion through dentin discs has been used to assess the behavior of dentin bonding agents under conditions 
encountered in the oral environment. In 1996, a direct contact test assay designed to evaluate water insoluble antibacterial materials. ${ }^{(2,3)}$

A guide to the potential antimicrobial activity of dentin bonding agent may be gained from an assessment of its $\mathrm{pH}$ when added to bacteriological culture medium. The direct contact method gives a better reflection of the killing bacteria in infected dentine than other method. ${ }^{(4)}$

Excite bond is a fifth- generation totaletch dentin bonding agent including dry and wet techniques, rely on etching the dentin and removal of the smear layer. This technique involves a separate etch and rinse step followed by priming and application of the bonding resin. ${ }^{(5)}$

G-Bond is a seventh-generation systems introduced in late 2002 and combined etchant, primer, and adhesive in a single bottle. ${ }^{(6)}$

Single bond is a fifth-generation onebottle adhesives, which can be used with a wet-bonding technique. ${ }^{(7)}$

E. faecalis was used for the susceptibility tests, because of its implication in endodontic failures and in primary root canal infections. ${ }^{(8)}$ S. mutans was used as it is the common bacteria in dental caries and in the oral cavity. ${ }^{(9)}$

The aims of this study were to determine and compare the antibacterial effect of the dentin adhesives (G-Bond, Single bond, and Excite bond) against E. faecali and $S$. mutans. Also, to evaluate the antibacterial effect at different time intervals (24, 48, and 72) hrs.

\section{MATERIALS AND METHODS}

Materials Tested:

Material used in this study were GBond (GC corporation, Tokyo, Japan), Single Bond (SB) (3M ESPE, St. Paul, MN, USA), and Excite (Ivoclar, Vivadent, AG FL-9494, Shaan/Liechtenstein). G Bond containing Methacryloyloxyethyl Trimellitate (4- MET), phosphoric ester monomer, UDMA, acetone, and camphorquinone. SB containing Bis-GMA, HEMA, dimethacrylates, water, ethanol, polyalkenoica acid, copolymer, and photoinitiator. Excite bond containing 2Hydroxyethyl- methacrylate (HEMA), dimethacrylates, phosphoric acid acrylate, silicon dioxide, and initiators and stabilizers in an ethanol solution. All adhesives were applied and photopolymerized following manufactures instructions. A LEDition curing unit (Ivoclar, Vivadent) was used for light polymerization for 20 seconds..$^{(10,11)}$

\section{Test Microorganisms:}

Microorganisms tested in this study were E. faecalis and S. mutans isolated from clinical cases. E. faecalis was isolated from teeth with periapical lesion (non exudative) and $S$. mutans was isolated from dental caries, in which each bacteria was cultured on isolated selective media. Inoculums on brain heart infusion broth (BHI) (Oxiod LTD, Basingstoke, Hants/ England) of each bacteria $\left(10^{8} \mathrm{cfu} / \mathrm{ml}\right)$ was then prepared. ${ }^{(10,11)}$

\section{Agar Diffusion Test (ADT):}

Dentin discs with a $6 \mathrm{~mm}$ diameter and $2 \mathrm{~mm}$ thickness were cut from non carious human molars, one disc was obtained from each tooth (from the middle third of the tooth). Dentin discs were then sterilized by autoclave $\left(121{ }^{\circ} \mathrm{C}\right.$ for $\left.1 \mathrm{~h}\right)$. After that, dentin disc was coated with one of the tested materials. Following light polymerization, the coated discs were applied face on down to the surface of E. faecalis agar plate (Difco Laboratories Detroit Michigan. USA) for E. faecalis, and on to Elliker agar plate for $S$. mutans (selective culture media for $S$. mutans. Compositions: ascorbic acid $0.5 \mathrm{~g} / \mathrm{L}$, casein enzymic hydrolysate 20 $\mathrm{g} / \mathrm{L}$, dextrose $5 \mathrm{~g} / \mathrm{L}$, gelatin $2.5 \mathrm{~g} / \mathrm{L}$, lactose $5 \mathrm{~g} / \mathrm{L}$, saccharose $5 \mathrm{~g} / \mathrm{L}$, sodium acetate 1.5 $\mathrm{g} / \mathrm{L}$, sodium chloride $4 \mathrm{~g} / \mathrm{L}$, and yeast extract $5 \mathrm{~g} / \mathrm{L}$. pH $\left.6.2 \pm 0.2\left(25^{\circ} \mathrm{C}\right)\right)$, and prepared according to Harrigan et al ${ }^{(12)}$, in which the two agar plates were inoculated by $10 \mu \mathrm{l}$ of one of the tested bacteria. Also, one disc without coating was placed on each plate (negative control). The plates were incubated at $37^{\circ} \mathrm{C}$ for $48 \mathrm{~h}$. After that, plates were inspected for the presence of inhibition zones around discs. The diameter of inhibition zone in milimeters was measured twice (along perpendicular lines). This test repeated ten times, and new dentin discs were used in each repeated time. ${ }^{(11)}$

Direct Contact Test:

The direct contact test was performed in 96 well microtiter plates (96 MicroWell Plates, China) (as shown in Figure (1)) 
following method of Weiss et al ${ }^{(13)}$ and Giammanco et $a l^{(11)}$. Materials tested were applied with sterile microbrush to the side wall of four wells of the microtiter plate and light polymerized. Ten microliters of the one of the tested bacterial inoculum (18 $\mathrm{h}$ growth) was placed on the polymerized materials and allowed for direct contact between bacteria and tested materials for $1 \mathrm{~h}$ in humid atmosphere at $37^{\circ} \mathrm{C}$. BHI broth $(250 \mu \mathrm{l})$ was then added to each well and gently mixed for 2 minutes. one set of four uncoated wells served as positive control and were inoculated with $10 \mu \mathrm{l}$ of bacterial suspension and then $250 \mu$ l of BHI broth was added to each wells. The negative control consisted of one set of four coated wells containing $250 \mu \mathrm{l}$ of uninoculated BHI broth. Also another set of

a

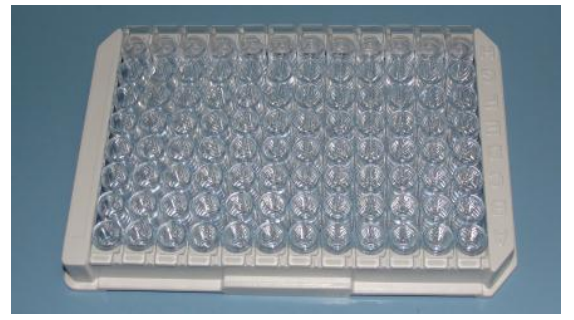

four uncoated wells containing $250 \mu \mathrm{l}$ of BHI broth (as blank). Plates were then incubated at $37^{\circ} \mathrm{C}$. The bacterial growths were monitored by spectrophotometer (CEIL CE 1021, England) (as shown in Figure (1)) in microplate reader recording the absorbance value (bacterial growth) at $590 \mathrm{~nm}$ after 24, 48, and 72 hours. At each recording time, the mean absorbance value (bacterial growth) of each tested materials was calculated from negative control wells and it was subtracted from the value obtain from tested materials contacting bacterial suspension, and positive control was obtained by subtracting its value from the blank. All experiments were carried out under aseptic conditions and repeated ten times to ensure reproducibility.

b

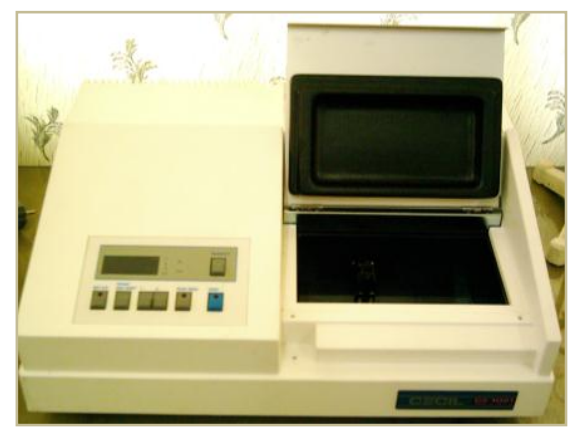

Figure (1): (a) Microtiter plates. (b) Spectrophotometer.

\section{RESULTS}

One way analysis of variance and Tukey post Hoc multiple range tests $(P \leq 0.05)$ were performed to evaluate the differences on antibacterial effect among tested materials. One way analysis of variance demon- strated significant differences of the antibacterial effect among tested materials against the two examined bacteria using agar diffusion test and direct contact test as shown in table (1).

Table (1): One way analysis of variance for the differences on the antibacterial effect of the tested materials using agar diffusion test and direct contact test.

\begin{tabular}{|c|c|c|c|c|c|c|}
\hline Bacteria type & & Sum of Squares & df*** & Mean Squares & F-value & $P$-value ${ }^{*}$ \\
\hline $\mathrm{ADT}^{1}$ & Between Groups & 396.867 & 2 & & \multirow{3}{*}{30.424} & \multirow{3}{*}{0.000} \\
\hline \multirow[t]{2}{*}{ S. mutans } & Within Groups & 176.1 & 27 & $\begin{array}{c}198.433 \\
6520\end{array}$ & & \\
\hline & Total & 572.967 & 29 & & & \\
\hline ADT & Between Groups & 408.267 & 2 & & \multirow{3}{*}{47.844} & \multirow{3}{*}{0.000} \\
\hline \multirow{2}{*}{ E. faecalis } & Within Groups & 115.2 & 27 & 204.133 & & \\
\hline & Total & 523.467 & 29 & & & \\
\hline $\mathrm{DCT}^{2}$ & Between Groups & 51.882 & 11 & & \multirow{3}{*}{65.358} & \multirow{3}{*}{0.000} \\
\hline \multirow[t]{2}{*}{ S. mutans } & Within Groups & 7.794 & 108 & 4.717 & & \\
\hline & Total & 59.676 & 119 & & & \\
\hline \multirow{3}{*}{$\begin{array}{l}\text { DCT } \\
\quad \text { E. faecalis }\end{array}$} & Between Groups & 56.316 & 11 & & \multirow{3}{*}{349.218} & \multirow{3}{*}{0.000} \\
\hline & Within Groups & 1.583 & 108 & 5.12 & & \\
\hline & Total & 57.899 & 119 & 0.015 & & \\
\hline
\end{tabular}


Agar diffusion test:

Results showed that $\mathrm{G}$ and SB bonds had antibacterial effect against the two examined bacteria significantly different from Excite bond. However, $\mathrm{G}$ bond had antibacterial effect significantly higher than SB bond. This was shown in table (2) and figure (2)

Table (2): Tukey test for the differences on the antibacterial effect of the tested materials using agar diffusion test.

\begin{tabular}{ccc}
\hline \multirow{2}{*}{ Tested Materials } & \multicolumn{2}{c}{ Inhibition Zone Mean $(\mathbf{m m}) \pm$ SD } \\
\cline { 2 - 3 } Control & S. mutans & Eaecalis \\
& $0.0 \pm 0.0$ & $0.0 \pm 0.0$ \\
G bond & $\mathrm{A}$ & $\mathrm{A} *$ \\
& $19.2 \pm 1.73$ & $16.4 \pm 1.77$ \\
Single bond & $\mathrm{D}$ & $\mathrm{D}$ \\
& $14.4 \pm 1.64$ & $12.6 \pm 1.5$ \\
Excite bond & $\mathrm{C}$ & $\mathrm{C}$ \\
& $10.3 \pm 1.05$ & $7.3 \pm 1.8$ \\
& $\mathrm{~B}$ & $\mathrm{~B}$ \\
\hline
\end{tabular}

*The different letters vertically mean significant difference exist.
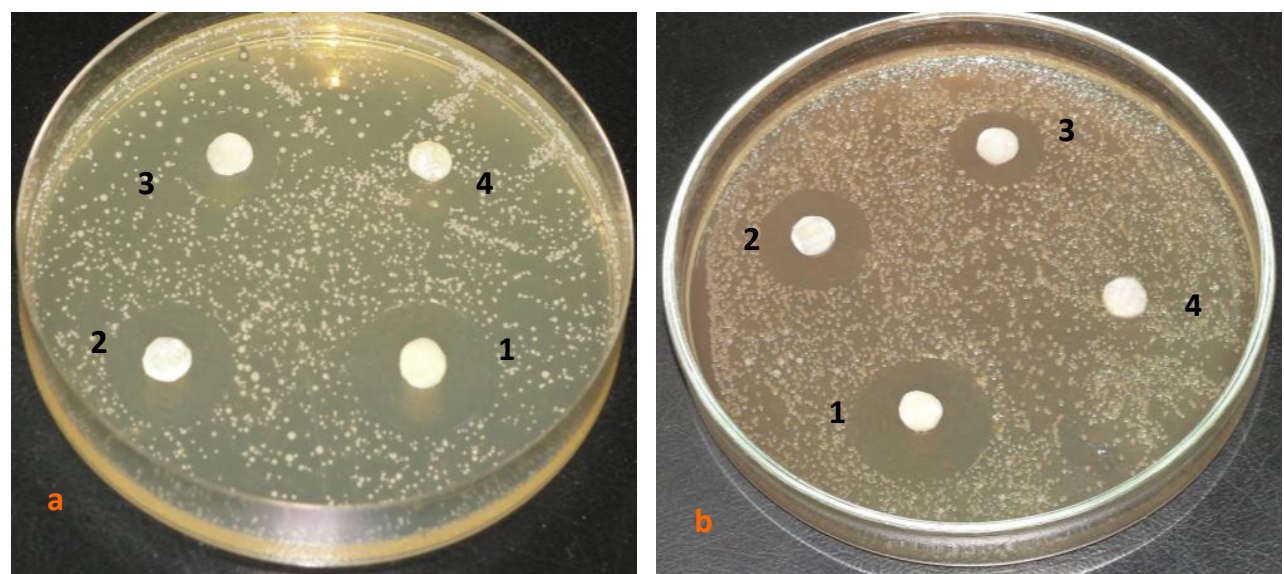

Figure (2): Inhibition zone of the tested materials against $S$. mutans and E. faecalis. $\mathrm{a}=S$. mutans $(1=\mathrm{G}$ bond, $2=\mathrm{SB}, 3=$ Excite bond, $4=\mathrm{control}-\mathrm{ve})$ on Ellikar agar plate. $\mathrm{b}=$ E. faecalis $(1=\mathrm{G}$ bond, $2=\mathrm{SB}, 3=$ Excite bond, $4=\mathrm{control}-\mathrm{ve})$ on E. faecalis agar plate.

\section{Direct Contact Test:}

Result showed that all tested materials had antibacterial effect against the tested bacteria significantly different from control positive group at different time intervals. Result also revealed that at each time interval group treated with $\mathrm{G}$ bond had highest antibacterial effect against the two tested bacteria, which was significantly different of antibacterial effect between SB and Excite bonds against $S$. mutans and $E$. faecalis at each time intervals, except that SB bond had no significant antibacterial effect against $E$. faecalis from group treated with
Excite at $24 \mathrm{~h}$. Comparing the results at different time intervals for each tested groups alone, it was clear that the groups treated with $\mathrm{G}$ bond had no significant difference among different time intervals against the two tested bacteria. While, SB and Excite bonds had no significant difference between $24 \mathrm{~h}$ and $48 \mathrm{~h}$ against two tested bacteria, but the antibacterial effect against two tested bacteria at $24 \mathrm{~h}$ and $48 \mathrm{~h}$ was significantly different from $72 \mathrm{~h}$ of treatment contact. This is shown in Tables (3) and (4). 
Table (3): Tukey test for the differences on the antibacterial effect of the tested materials using direct contact test.

\begin{tabular}{|c|c|c|c|c|c|c|}
\hline \multirow{3}{*}{ Tested Materials } & \multicolumn{6}{|c|}{ Absorbance Mean $(\mathrm{nm}) \pm$ SD at Different Time Intervals } \\
\hline & \multicolumn{3}{|c|}{ S. mutans } & \multicolumn{3}{|c|}{ E. faecalis } \\
\hline & $24 \mathrm{~h}$ & $48 \mathrm{~h}$ & $72 \mathrm{~h}$ & $24 \mathrm{~h}$ & $48 \mathrm{~h}$ & $72 \mathrm{~h}$ \\
\hline \multirow{2}{*}{ Control } & $0.88 \pm 0.7$ & $1.77 \pm .15$ & $2.4 \pm .8$ & $0.91 \pm 0.06$ & $1.85 \pm 0.6$ & $2.6 \pm 0.23$ \\
\hline & $A^{*}$ & A & A & A & A & $\mathrm{A}$ \\
\hline \multirow{2}{*}{ G bond } & $0.17 \pm 0.05$ & $0.19 \pm 0.1$ & $0.22 \pm 0.17$ & $0.19 \pm 0.04$ & $0.22 \pm 0.09$ & $0.24 \pm 0.12$ \\
\hline & D & $\mathrm{D}$ & D & D & D & D \\
\hline Single bond & $0.39 \pm 0.15$ & $0.42 \pm 0.13$ & $0.55 \pm 0.15$ & $0.45 \pm 0.05$ & $0.49 \pm 0.1$ & $0.66 \pm 0.06$ \\
\hline \multirow{2}{*}{ Excite bond } & $0.64+0.04$ & $0.69+0.22$ & $182+0.11$ & $0.54+0.06$ & $0.58+0.14$ & $19+0.14$ \\
\hline & B & $\mathrm{B}$ & B & $\mathrm{C}$ & B & B \\
\hline
\end{tabular}

*The different letters vertically mean significant difference exist.

Table (4): Tukey test for the differences on the antibacterial effect of the each tested materials at different time intervals using direct contact test.

\begin{tabular}{cccc|ccc}
\hline & \multicolumn{4}{c}{ Absorbance Mean(nm) \pm SD at Different Time Intervals } \\
\cline { 2 - 7 } Tested Materials & \multicolumn{3}{c}{$\boldsymbol{S . ~ m u t a n s}$} \\
\cline { 2 - 7 } & $\mathbf{2 4} \boldsymbol{h}$ & $\mathbf{4 8} \boldsymbol{h}$ & $\mathbf{7 2 ~ h}$ & $\mathbf{2 4} \boldsymbol{h}$ & $\mathbf{4 8} \boldsymbol{h}$ & $\mathbf{7 2 ~} \boldsymbol{h}$ \\
\hline \multirow{2}{*}{ Control } & $0.88 \pm 0.7$ & $1.77 \pm .15$ & $2.4 \pm .8$ & $0.91 \pm 0.06$ & $1.85 \pm 0.6$ & $2.6 \pm 0.23$ \\
& $\mathrm{~A}$ & $\mathrm{~B}$ & $\mathrm{C}$ & $\mathrm{A}$ & $\mathrm{B}$ & $\mathrm{C}$ \\
G bond & $0.17 \pm 0.05$ & $0.19 \pm 0.1$ & $0.22 \pm 0.17$ & $0.19 \pm 0.04$ & $0.22 \pm 0.09$ & $0.24 \pm 0.12$ \\
& $\mathrm{~A}$ & $\mathrm{~A}$ & $\mathrm{~A}$ & $\mathrm{~A}$ & $\mathrm{~A}$ & $\mathrm{~A}$ \\
Single bond & $0.39 \pm 0.15$ & $0.42 \pm 0.13$ & $0.55 \pm 0.15$ & $0.45 \pm 0.05$ & $0.49 \pm 0.1$ & $0.66 \pm 0.06$ \\
& $\mathrm{~A}$ & $\mathrm{~A}$ & $\mathrm{~B}$ & $\mathrm{~A}$ & $\mathrm{~A}$ & $\mathrm{~B}$ \\
Excite bond & $0.64 \pm 0.04$ & $0.69 \pm 0.22$ & $1.82 \pm 0.11$ & $0.54 \pm 0.06$ & $0.58 \pm 0.14$ & $1.9 \pm 0.14$ \\
& $\mathrm{~A}$ & $\mathrm{~A}$ & $\mathrm{~B}$ & $\mathrm{~A}$ & $\mathrm{~A}$ & $\mathrm{~B}$ \\
\hline
\end{tabular}

*The different letters horizontally for each tested bacteria alone mean significant difference exist.

\section{DISCUSSION}

The antibacterial effect of the tested materials used in this study was performed after curing which was resembled to those encountered in the restorative treatment of dental caries.

The resin monomer 12-methacr yloyloxydodecylpyridinium bromide (MDPB) has been incorporated in the composition of some bonding systems to enhance the antibacterial effect of these materials. $^{(14)}$

Although all the tested bonding agents used in this study does not containing MDPB, but they are exhibit significant antibacterial effect from that of control group by the two tests and against the two examined bacteria. Giammanco et al (11) compared the antibacterial effect of dentin/enamel adhesive systems containing MDPB and not containing MDPB. Results found that the antibacterial effect does not seem to be entirely linked to the presence of the immbolized antimicrobial MDPB, since the resin not incorporating MDPB also exhibited comparable bacteriostatic activity. They concluded that both materials tested delay bacterial growth equally. Imazato et $a l^{(14)}$ reported that the antimicrobial effect of the dentin/enamel adhesives containing both MDPB and MDP (10-Methacry oyloxydecyl dihydrogn phosphate) is equivalent to that not containing MDPB.

Therefore, the antibacterial effectiveness of the dental materials used in this study was related to several factor including: experimental methods, physical properties (mainly viscosity), $\mathrm{pH}$, and chemical composition (acid, ethanol, acetone, and even the component that had been add to increase adhesion (HEMA)). ${ }^{(15)}$

The Direct contact test is considered to be the most valuable in vitro assay to study the antimicrobial properties of dental materials. It has the ability to follow bacte- 
rial growth in both the presence and absence of the tested material, allowing not only the direct contact effect, but also the effect of those components which are capable of diffusing into the liquid medium to be measured. ${ }^{(13,16)}$

In this experimental study, preferable antibacterial effect using the two tests and against the two tested microorganisms was observed by $G$ bond which was significantly different from SB and Excite bond. This could be attributed to the acidity of G-Bond and viscosity of the material which influences their abilities to penetrate into demineralized dentin so that the primer impregnated and cured in dentinal lesion should inhibit invading bacteria within the lesion more effectively. G-Bond is acetone-based so it has high affinity with demineralized wet dentin and inhibits invading bacteria. ${ }^{(17)}$

It was found in this study that there was no significant differences on the antibacterial effect between Single bond and Excite bond.

Single bond and Excite bond contains 2-hydroxyethylmethacrylate (HEMA), this component was in part aided the antibacterial effect of these materials by providing a low $\mathrm{pH}^{(18)}$

Excite bond, although presenting low $\mathrm{pH}$ (1.7) as reported by previous study ${ }^{(19)}$ due to the presence of phosphoric acid acrylates in its composition, it did not show high inhibitory activity against bacterial strains tested in this study. It is believed that some physical characteristics of the material are important in modulating the antibacterial activity. While Excite has alcohol as solvent, it is presented as a viscous fluid due to the inclusion of filler particles into its composition, which could prevent this material from diffusing properly in the agar medium. As a consequence, the $\mathrm{pH}$ drop was not intense enough to reach the lethal $\mathrm{pH}$ values reported for S. mutans (3.5-3.0) ${ }^{(20)}$, but this drop on $\mathrm{pH}$ made it is effective against $E$. faecalis (lethal $\mathrm{pH}$ was under 7 and above 12.5).

The Single bond system, has a $\mathrm{pH}$ of 5.0 as reported by previous study ${ }^{(19)}$, which is not acidic enough to prevent $S$. mutans from maintaining their metabolism at the same time it is effective against $E$. faecalis. It should be considered the possibility that the use of mildly acidic materials could, instead of having a detrimental effect on bacterial growth, stimule the generation of more resistant strains. This observation is in line with the results reported by Atac et al ${ }^{(21)}$

The antibacterial effect of Single bond and Excite bond against $S$. mutans may be related to their chemical antibacterial components (acid and ethanol). However, it is relevant to remember that these (Single bond and Excite bond) are two-steps etch-and-rinse adhesive systems which are used after the previous application of phosphoric acid as away to superficially demineralize the substrate. It has been demonstrated that phosphoric acid has antibacterial activity and causes a significant immediate reduction in the number of microorganisms in carious dentin. ${ }^{(22)}$

On the basis of the results obtained and of the experimental conditions used in this study, it can be concluded that $\mathrm{G}$ bond was able to delay bacterial proliferation more effectively than SB and Excite bond during restorative treatment of dental caries. However, further investigations are necessary for better understanding the exact mechanism of the antibacterial effect of different components of the adhesives tested in this study.

\section{CONCLUSIONS}

All types of dentin bonding agent used in this study had antibacterial effect in which $\mathrm{G}$ bond had more preferable and highest effect among them. Therefore, G bond can be consider as the most effective agent to delay bacterial growth during restorative treatment of dental caries.

\section{REFERENCES}

1. Kidd EA, Ricketts DN, Beighton ND. Criteria for caries removal at the enameldentine junction: a clinical and microbiological study. Braz Dent J. 1996; 180:287-291.

2. Schmalz G, Ergucu Z, Hiller KA. Effect of dentin on the antibacterial activity of dentin bonding agents. J Endod. 2004; 30:352-358.

3. Ratledge DK, Kidd EA, Beighton D. A clinical and microbiological study of a 
proximal carious lesions. Part 2: efficacy of caries removal following tunnel and class II cavity preparations. Caries Res. 2001; 35:8-11.

4. Cobnkara FK, Altinoz HC, ErganiI O, Kav $\mathrm{K}$, Bellis. In vitro antibacterial activities of root canal sealers by using two different methods. J Endod. 2004; 30:57-60.

5. Kanca J. A method for bonding to tooth structure using phosphoric acid as a dentin enamel conditioner. Quin Int. 1991; 22:285-90.

6. Ibrahim H, Hagag E, Manal. Microleakage of nanofilled composite resin restorative material. J Biomat Nanobiotech. 2011; 2:23-26.

7. Kuramoto S, Imazato1 AWG, Walls, Ebisu S. Inhibition of Root Caries Progression by an Antibacterial Adhesive. J Dent Res. 2005; 1:89-93.

8. Pirani C, Bertacci A, Cavrini F, Foschi F, Acquavivag L, Prati C, Sambari V. Recovery of Enterococcus faecalis in root canal lumen of patients with primary and secondary endodontic lesions. New Microbiol. 2008; 31:235-240.

9. Satoshi I, Akiko K, Yusuke T, Shigeyuki E, Mathilde C. Petersb. In vitro antibacterial effects of the dentin primer of Clearfil Protect Bond. Dent Mater. 2006; 22:527532.

10.Lobo MM, Goncalves RB, Pimenta LA, Bedran-Russo AK, Pereira PN. In vitro evaluation of caries inhibition promoted by self-etching adhesive systems containing antibacterial agents. J Biomed Mater Res B Appl. 2005; 75:122-127.

11. Giammanoco GM, Cumbo EMG, Luciani A, Gallina G, Caterina M, Pizzo G. In vitro evaluation of the antibacterial activity of cured dentin/enamel adhesive incorporating the antimicrobial agent MDPB. New Microbiol. 2009; 32:385-390.

12.Harrigan WF, McCance ME. Laboratory method in food and diary microbiology. Rev.ed., London academic press. New York. San-Francisco. 1976; 88-89.
13. Weiss EI, Shalhav M, FUSS Z. Assessment of antibacterial activity of endodontic sealers by a direct contact test. Endod Dent Traumatol. 1996; 12:179-184.

14.Imazato S, Kinomoto Y, Tarumi H, Ebisu S, Tay FR. Antibacterial activity and bonding characteristic of an adhesive resin containing antibacterial monomer MDBP. Dent Mater. 2003; 19:313-319.

15.Imazato S, Torii Y, Takatsuka T, Inoue K, Ebi N, Ebisu S. Bactericidal effect of dentin primer containing anti

16.bacterial monomer methacryloyloxydodecylpyridinium bromide (MDPB) against bacteria in human carious dentin. $\mathbf{J}$ Oral Rehab. 2001; 28:314-319.

17.Vaidyanathana M, Shechyb EC, Giberth SC, Beightonab D. Antimicrobial properties of dentine bonding agents determined using in vitro and ex vivo methods. J Dent. 2009; 37:519-521.

18. Vivany S and Vasundhara S. Comparative evaluation of microleakage of fifth, sixth, and seventh generation dentin bonding agents: An in vitro study. J Conser Dent. 2010; 13:136-140.

19. Abdel-Wahab S, Habib ANA, Abu El Emm N. Antibacterial Effect of an Antibacterial adhesive system, and a resin modified glass ionomer liner. Suez Canal Univ Med J. 2008; 11:9-12.

20.Duque C, Negrini TC, Spolidorio DMP, Hebling J. Effect of light-activation on the antibacterial activity of dentin bonding agents. Braz J Oral Sci. 2009; 8:175-180.

21. Sehreli ZC, Stephan A, Sener B. Antimicrobial properties of self-etching primerbonding system. Oper Dent. 2003; 28:143148.

22. Atac AS, Lehreli ZC, Sener B. Antibacterial activity of fifth-generation dentin bonding systems. J Endod. 2001; 27:730733.

23. Wicht MJ, Haak R, Kneist S, Noack MJ. A triclosan-containing compomer reduces Lactobacillus spp. predominant in advanced carious lesions. Dent Mater. 2005; 21:831-836. 